\title{
Development of Functional Symptoms in Children Exposed to Traumatic Events
}

\author{
Paula A. Madrid and Robert K. Kanter
}

\begin{abstract}
This chapter will review the typical symptoms occurring in children after stressful traumatic exposures. Unlike other chapters in this book, no specific organ system is the most likely focus of functional symptoms in this setting. Psychological distress may exacerbate symptoms of physical illness and injury associated with the traumatic events, may be expressed as almost any seemingly unrelated symptom, may intensify the age appropriate fears typical of any child, or may predominantly be exhibited behaviorally. In most nonsevere cases, the impact is self-limited and the individual's functioning will be back to normal within days or weeks. We will suggest simple behavioral and environmental interventions intended to help relieve children's distress. However, when large populations are affected and individuals suffer severe loss such as in a mass casualty disaster, the scale of events requires community-wide efforts to meet the needs of children and their families. The fact that some children are more psychosocially vulnerable than others will be discussed. The chapter will conclude by highlighting warning signs warranting professional mental health care.
\end{abstract}

\section{Keywords}

Children $\bullet$ Trauma $\bullet$ Behavior $\bullet$ Mental health $\bullet$ Disaster $\bullet$ Mass casualty

P.A. Madrid, PsyD

Harvard Program in Refugee Trauma, Columbia University's Mailman School of Public Health, New York, NY, USA

R.K. Kanter, MD (四)

Department of Pediatrics, SUNY Upstate Medical University, Upstate Golisano Children's Hospital, 750 E. Adams Street, Syracuse, NY 13210, USA e-mail: kanterr@upstate.edu

\section{Introduction}

When physical or emotional harm occurs to oneself, a loved one, or even when witnessing harm to a stranger, most people experience the event as emotionally upsetting. Likewise, the loss of important possessions and major disruptions of routines can be distressing. Stressful exposure to traumatic events is an inevitable consequence of human existence. Such stress may occur as a result 
of accidental or intentional violence involving individuals or affecting a large population as in mass casualty disasters.

\section{Child Anxiety}

All children exhibit some form of anxiety according to their developmental stage. Children fear pain and bodily harm at all ages. Older infants and toddlers are fearful of strangers, absence of parents/caregivers, and unfamiliar situations. Children at preschool ages may be afraid of the dark, animals, separation from home and family, and the possibility of harm occurring to parents or caregivers. Older children and adolescents often feel anxiety about school performance, social competence, independence, privacy, and death. Traumatic events are experienced as threats that intensify usual age appropriate childhood anxiety. When stressed, children often regress to anxieties and behaviors typical for a younger developmental level [1]. The anxiety manifested as a result of exposure to trauma intensifies age-appropriate childhood anxieties.

\section{Epidemiology of Stress Responses: Everyday Traumatic Events}

Most children experience a traumatic event at some time, and these events are often brought to the attention of a primary care physician. Thus primary care providers are in an ideal position to screen and provide preliminary support for children who might otherwise remain without help. Likewise, emergency physicians often have the opportunity and responsibility to identify and help children with mental health emergencies [2].

Children's stress reactions tend to be proportional to the suddenness of onset, the severity of life threat, injury, exposure to the grotesque, separation from caregivers, physical losses, and the severity of environmental disruption [3]. For instance, after being directly involved in a motor vehicle accident, $11 \%$ of adolescents reported subsequent stress-related symptoms (Table 17.1), fear, and depression. These symptoms exceeded
Table 17.1 Common early symptoms

\begin{tabular}{l}
\hline Emotional reactions \\
\hline Fear \\
\hline Shock \\
\hline Disbelief \\
\hline Feeling overwhelmed \\
\hline Feeling hopeless \\
\hline Feeling numb \\
\hline Panic attacks \\
\hline Behavioral reactions \\
\hline Sleep disturbance \\
\hline Hypervigilance \\
\hline Irritability \\
\hline Exaggerated startle \\
\hline Aggressive outbursts \\
\hline Apathy \\
\hline Withdrawal from interactions \\
\hline Separation anxiety \\
\hline Regression to less mature behavior \\
\hline Cognitive symptoms \\
\hline Difficulty concentrating \\
\hline Difficulty making decisions \\
\hline Poor attention span \\
\hline Loss of memory \\
\hline Treoccupation with unpleasant memories \\
\hline Tacholigurar symptoms \\
\hline
\end{tabular}

stress symptoms in a control population. Adolescents who witnessed a motor vehicle accident also had an increased risk of such symptoms even when they were not directly involved $[4,5]$. Fourth-grade children who witnessed the accidental deaths of two adults at a school were so upset that many could not attend school for several days. Then symptoms of stress rapidly declined in subsequent days [6]. Traumatic events occurring within a family, whether physical or sexual abuse, emotional maltreatment, neglect, sibling victimization, or witnessing family violence, are especially likely to cause stress symptoms [7]. 


\section{Epidemiology of Stress Responses: Disasters}

Disasters involving large numbers of illnesses, injuries, deaths, and community disruption trigger similar stress responses as everyday traumatic events. However, because of the widespread exposure to distressing events and disruption of therapeutic services, the impact may be exaggerated and last longer. Even when a public health emergency caused few life-threatening implications for the population, community disruption and environmental hazards resulted in one-third of parents reporting physical symptoms or mental health issues that affected their children after the 2010 Gulf Coast oil spill [8]. Likewise, as measured by the proportion of children receiving counseling, $22 \%$ of children in Manhattan experienced significant stress-related symptoms in the aftermath of the September 11, 2001 attack [9]. Media coverage of emergencies is often intense, so that exposure to the disturbing events is repetitive. It has been found that media coverage may provoke stress responses in individuals remote from the events who suffered no direct involvement to themselves or loved ones [10]. Thus, immediately after exposure to a traumatic event, virtually all children and adults may exhibit stress-related symptoms and behaviors, and this is well within the normal range of responses.

\section{Common Early Symptoms After Traumatic Events}

The early symptoms of traumatic stress include emotional reactions [11-13]. It is common to feel fear, shock, disbelief, and seemingly being overwhelmed, helpless, or numb. More serious symptoms may include dissociation and panic attacks. Common cognitive deficits include difficulty concentrating or making decisions, shortened attention span, loss of memory, or preoccupation with unpleasant memories. Physical symptoms may include gastrointestinal distress, headaches, nausea, dizziness, tachycardia, tremor, generalized pain, and fatigue. The clinician may find increased arousal manifested by increased blood pressure and heart rate. Hypervigilance, sleep disturbance, irritability, exaggerated startle response, and aggressive outbursts are common behaviors [14]. Immediately after a traumatic event, such symptoms and signs may confuse the diagnostic evaluation of physical injuries (see Table 17.1).

After traumatic events, individuals may be irritable and behave aggressively or may become sad, apathetic, and withdraw from interaction. For example, the mutism of many unaccompanied injured children immediately after a tornado interfered with medical history taking, and delayed family reunification [15]. Age-specific trends may be noted. Toddlers and young children are likely to demonstrate increased crying, separation anxiety, clingy behavior, sleep terrors, nightmares, and tantrums. School age children display aggressive or thematic play (reenactments, ritualistic interactions and a fascination with a particular person, toy, or character), specific phobias, sleep disturbance, physical complaints, withdrawal, regressed behavior including enuresis, thumb-sucking, clinginess, baby talk, asking for a bottle, and separation anxiety. Adolescents may be depressed, anxious, withdrawn, do poorly in school, be irritable, deny that a permanent change has taken place, or engage in risk-taking behavior. Adolescents may attempt to mask symptoms, fearing that their reactions might seem abnormal. For the majority of children, as long as they do not experience further stressors, such symptoms usually diminish over days or a few weeks.

\section{Simple Early Interventions for Children Exposed to Traumatic Events}

Any emergency care, primary care, school health, or subspecialist provider may be able to help children and their families by giving simple advice in the immediate aftermath of a traumatic event. Family collaboration is a must whenever possible.

- Reunify the child with family members at the earliest possible time, when relative is not the perpetrator of trauma. 
- Provide transitional toys, safety blankets, or other coping toys to younger children.

- Reassure the child or family member honestly that "keeping you safe is the most important thing to me," and "we will do everything we can to find your parents."

- Give the child realistic, age-appropriate hope.

- Maintain familiar routines whenever possible (family, school, church).

- Identify concrete needs and try to help meet them.

- Listen to the child. The amount of information given to the child depends on what s/he wants, for which s/he is ready.

- Do give children information about the event. $\mathrm{Be}$ aware of information the child is receiving on television, the Internet, and what s/he has actually seen on the street.

- Encourage children to express feelings in words, play, behavior, and drawings or other art forms.

- Keep in mind that children's responses may be confusing and confused. Denial does not mean the child is not distressed or unaware.

- Children are resilient if supported by adults. Adults who model effective coping behavior promote healthy coping skills by children [16].

\section{Organizational Approach to Mental Health Services After Disasters}

A surge in population needs for mental health services may be anticipated when large numbers have experienced risk and traumatic events, especially if accompanied by restriction in their movement, limitation in resources, and inadequate information [17]. Restoring communications systems will reduce the sense of isolation, provide the public with information to avoid hazards, and promote population safety, as well as relieve anxiety associated with separation from loved ones. Child safety, identification, and reunification procedures improve efficiency and effectiveness of all other services [18].

School resources have been vital in supporting community-wide early efforts to help children and families cope with the traumatic experiences of a disaster [16, 19-21]. Important opportunities include early availability of the school as a safe environment that restores familiar routines. School administrative resources may be useful in contacting all families and staff to determine needs and to coordinate ongoing assistance with housing, childcare, and health care. School-based group counseling may be an efficient way of providing simple interventions for large numbers of children. School-based screening also identifies those whose greater needs warrant referral for professional mental health care (see below). "Just-intime training," brief educational sessions focused on a specific set of problems and solutions, optimizes the role of schoolteachers in helping children, and recognizing severe mental health problems.

\section{Vulnerability for Severe Mental Health Disorders After Traumatic Events}

Children with the most severe traumatic experiences are at greatest risk for severe and prolonged mental health disorders, whatever the prior individual, family, or neighborhood factors predisposing to vulnerability or resilience [3, 22]. Greater threat to life or actual loss of life of a loved one, injury, exposure to the grotesque, victimization due to lawlessness, separation from caregivers, and physical losses all raise the risk of prolonged and severe mental health issues.

Some children's personal situations place them at greater risk of severe mental health consequences after a traumatic event. These risk factors include characteristics of the child (prior mental health problems, medically vulnerable), parents (poor mental health, low socioeconomic status), household (unstable housing, lost income, economically disadvantaged), and neighborhood (unsafe schools and community, social disorder) [23]. Children with any disabilities and special health care needs are likely to have greater risk of mental health consequences after traumatic events [24].

Also at risk may be children whose parents serve in the military. Children in military families experience family separations with the real threat 
of a parent's death or disabling injury, as well as the frequent need to move to a new community. Also families must cope with the stress responses of veterans returning from combat. In the opinion of one American military leader in 2012, adolescents in military families may feel that "my whole conscious life has been at war. The U.S. has never, never experienced that before" [25].

\section{Warning Signs of Severe Mental Health Disorders After Traumatic Events}

In addition to persistence of the common stress response symptoms described above, more severe manifestations must be recognized.

\section{Self-Injurious Behaviors}

Self-injury takes many common forms such as burning, cutting, interfering with wound healing, and scratching. It can also take the form of banging body parts, needle sticking and carving words or symbols into the skin [26], gouging, hairpulling or plucking, inserting harmful objects into the vagina or rectum, picking at cuticles and biting nails until bleeding occurs, biting oneself, digging into the gums, choking, hitting oneself with objects, ingesting sharp objects, and using an eraser to tear or burn the skin [27].

\section{Suicide Risk}

Childhood sexual abuse and neglect is a factor in increased vulnerability to suicidal ideation [28, 29] as are the presence of psychiatric disorders such as major depressive disorder, generalized anxiety disorder, panic disorder, attention-deficit hyperactivity disorder, conduct disorder, and substance use disorder [30]. Studies have also found that current alcohol consumption, use of illicit drugs, symptoms indicating conduct disorders are risk factors for suicidality for children 11-15 years of age [31]. Similarly, there are findings indicating a strong consensus that adolescent and adult men who report same-sex sexual orientations, identities, and behaviors are prone to experience trauma as a result of interactions with others that increases their suicide risk [32]. A study used regression analyses to determine whether children who experience childhood bullying behaviors are at risk for later suicide attempts and completed suicides after controlling for baseline conduct and depression symptoms. Its findings were that among boys, frequent bullying and victimization were associated with later suicide attempts and completed suicides. However, after controlling for conduct and depression symptoms, there was no identified association between bullying and suicidality. Frequent victimization among girls is associated with later suicide attempts and completed suicides, even after controlling for conduct and depression symptoms [33].

\section{Substance Abuse}

Adolescents with traumatic stress experiences are more likely to have issues with substance abuse and other risk-taking behavior [34].

\section{Sleep Disturbance}

Sleep disturbances are hallmark signs of trauma. These include nightmares, difficulty falling and remaining asleep, sleepwalking, night terrors, and bedwetting at night. Daytime functioning is also affected as a result of resultant fatigue and excessive daytime sleepiness [35].

\section{Regression}

Regression refers to a reversion to an earlier or less mature pattern of feeling or behavior. Regression is exhibited by children as a behavior that would be normally observed in an earlier stage of development. Bedwetting, clingy, whiney behavior, and engaging in baby talk are common [36]. Long lasting regression may indicate a persistent disorder warranting professional mental health evaluation. 


\section{Selective Mutism}

Selective mutism is a "childhood disorder that is characterized by the persistent failure to speak in at least one specific social situation, despite the ability to speak in other situations" [37]. Children who become mute in social settings tend to be talkative around family with whom they are familiar, but at school they might respond to queries with nonverbal signals such as gestures and nods. These children are sometimes either rigid or fidgety and may blush when communication is attempted. Efforts to force them to speak will result in an irritable disposition, an outright temper tantrum, or severe withdrawal.

\section{Cruelty to Animals}

It is important to distinguish between explorative play in which children "handle" animals such as insects causing unintentional harm versus torturing pets or other small creatures. Animal cruelty, like any other violence, should never be attributed to a stage of development and if allowed to harm animals, children are more likely to be violent later in life. Children who witnessed family violence were three times more likely to abuse animals than their peers [38].

\section{Inappropriate or Disturbing Play Behaviors}

Play is a major feature of childhood activity. Effects of traumatic experiences may be expressed in play. Play behaviors predictive of Posttraumatic Stress Disorder (PTSD) include frequent acting-out morbid themes and play at an immature developmental level [39].

\section{Poor Peer Relationships}

Children who have been maltreated are usually less socially competent and may be socially rejected by their peers. Traumatized children may have difficulty establishing or maintaining relationships or reading social cues [40]. Their interactions are often aggressive, belligerent, or rebellious.

\section{Poor School Performance}

Changes in school performance should be noted, and the causes explored. Elementary school performance is impaired by stressors found in a child's school, family, and/or neighborhood. Math and reading grades decline while depression and aggression rates increase [41]. Similarly, reading performance diminished for urban 2 nd through 5th graders who had experienced violence or the loss of a significant other [42]. Exposure to traumatic experiences is also a risk factor for school dropout [43].

\section{Inappropriate Sexual Behavior}

Children's sexual development begins at birth and progresses through peaks and troughs depending on their developmental stage and socialization. Some forms of sexual play are normal and expected at various ages of development. However, some sexual behaviors raise concern:

- Sexual experimentation with older children or those who are not their usual playmates.

- Sexual experimentation that results in other children making complaints.

- Undue shame, guilt, fear, or anxiety about sexual behavior.

- Child using warped reasoning to justify sexual behavior, for example, forcing another child to engage in sexual behavior and saying that the child really wanted to participate.

- Sexual interest that appears out of balance with other aspects of the child's life.

- Child engaging in persistent and extensive sexual behavior with another consenting child [44].

Sexually transmitted diseases may result from such behavior. Depending on the age of the child, pregnancy is a risk. 


\section{Separation Anxiety Disorder}

Separation Anxiety Disorder (SAD) refers to an abnormal reactivity to real or imagined separation from attachment figures. It interferes with daily activities and developmental tasks [45]. This occurs at a rate of 4-5\% among children, with an average onset age of 7.5 years old. Clinical help is usually sought after the child expresses somatic complaints and/or refuses to attend school. After the 2001 World Trade Center attack [46], the prevalence was $12.3 \%$ in school-aged children; 4th and 5th graders were three times more likely to have probable SAD than 9th through 12th graders. After the September 11 attacks, SAD was more likely for girls, for those directly exposed to the attacks, with relatives involved, and after extensive media exposure.

\section{Posttraumatic Stress Disorder}

PTSD involves a pattern of stress related symptoms including re-experiencing the stressful event repeatedly, avoidance of reminders of the experience, and hyperarousal, all lasting more than a month [12]. Repetitive experience of the event may include a vivid sense of reliving the event, nightmares, and recurrent physiological or emotional reactions to these stressful memories. Avoidance includes efforts to distance oneself from memories as well as from locations or images associated with the traumatic event. Impaired memory, feelings of detachment and estrangement, and feelings of hopeless inability to plan for the future may follow. Hyperarousal may include difficulty sleeping, angry outbursts, hypervigilance, and inappropriate startle responses. PTSD can impair home, school, and social functioning and must be distinguished from appropriate bereavement and sadness that may include recurrent thoughts, but does not unduly interfere with functioning.

\section{Referral and Treatment}

Severe symptoms interfering with function or suggesting the likelihood of self-destructive behavior are red flags. Simultaneously impaired functioning at home, school, and socially (interpersonally), as well as ongoing acute stress symptoms (longer than 1 month) call for (1) immediate psychiatric evaluation, and possibly hospitalization and (2) extended care, monitoring, or some form of ambulatory intervention [47].

Mental health professionals have a wide range of tools at their disposal for treating traumatized children.

There is support for the use of directive, trauma-focused therapy over nondirective, support-oriented techniques to reduce most child trauma symptoms [48]. Treatment approaches such as Trauma-focused Cognitive Behavioral Therapy [49] (Chap. 19), Prolonged Exposure [50] Cognitive Behavior Therapy of Childhood Sexual Abuse [49] as well as Semi-structured Interview Intervention [51], and Structured Play Therapy [52] (Chap. 28) have been widely used among many others.

It is essential to stress the importance of parents and caregivers to provide stressed and or traumatized children with a safe, consistent, and predictable environment. Immediate goals include stabilizing the home environment, making sure the threat has been removed, i.e., abusive member of the household is no longer a threat to the child and ensuring that caregivers are able to keep the child safe. Healthcare providers across disciplines must collaborate in these efforts. It is also very important for families to understand trauma and PTSD and its impact on the child's functioning. This may in turn provide the parent with the ability to normalize symptoms and reframe symptoms as signs of coping and protective healing mechanisms. It also encourages parents and caregivers to discuss and understand their own feelings about the event that caused the trauma in the child. Medical providers may also educate parents about anticipating a child's reactions during times of transition such as changes of school, holidays, and the anniversary of the traumatic event.

The psychological treatment of a child should always take place with parent/caregiver cooperation. This involves providing the caregiver with education about the child's condition and the best ways to help the child outside the therapy setting. 
Sometimes, it is necessary for providers to think of themselves as "detectives" in that children of all ages can mask the source of anxiety and depression from themselves and others. In situations where children and teens refuse to participate in specific activities, perseverate in certain behavioral activities, and deny worries even when nonverbal cues indicate stress, providers are encouraged to gently pursue the "child's world." Perhaps the physical or social environment is subtly reminiscent of the trauma, and the fear has generalized to unexpected people, places, and objects.

In caring for children after exposure to traumatic events, practitioners must take into account cultural considerations such as the way in which the child and his/her family think about and cope with stress, grief and loss, the forms of acceptable assistance, and religious beliefs.

\section{Case Studies}

1. A 6-year-old boy is involved in a car accident in which he is unharmed but his parents suffer cuts and bruises. Soon after the accident, he has a difficult time falling asleep unless he is with his parents, appears to have lost his appetite, is irritable, clingy, and becomes tearful more often than before. After 2 weeks and with continuous reassurance from his parents, the boy's behavior improves and gradually returns to his prior level of functioning.

What should the primary care provider do?
(a) Monitor the child for additional symptomatology.
(b) Talk to the parents about appropriate stress responses.
(c) Properly document incident for future reference.
(d) Inquire how the parents are doing.
(e) All of the above.

2. A 10-year-old girl witnesses her neighbor get shot in the street one afternoon. She becomes severely shocked, refuses to sleep on her on from that point on, and her parents agree to let her sleep with them for months. She also becomes severely withdrawn, appears to be "out of it" as she is often daydreaming and loses interest in her friends, all play activities, and in school. The patient's parents are mostly concerned about her academic performance but have not yet discussed her feelings regarding the event she witnessed. The patient's teachers believe she has become lazy and disinterested in school. She finally receives counseling 9 months after the incident because her parents become concerned that she may not be promoted from 5 th to 6th grade.

What should the primary care provider do?

(a) Encourage parents to actively participate in the girl's treatment.

(b) Coordinate treatment with her mental health provider in case she becomes a candidate for psychiatric medication and to monitor psychosomatic complaints.

(c) Normalize the girl's reactions by discussing common trauma response with her parents and ideally with teachers as well.

(d) All of the above.

(e) None of the above.

3. An 8-year-old boy's home is burned down in a fire that also destroyed four neighbors' homes. The boy was at home sleeping when firefighters save his life and that of his family. The boy and his family lose all of their possessions and are forced to move in permanently with their relatives in a nearby town. The boy is unable to return to his school and has heard that that his friend and neighbor died in the fire. His parents are so devastated by their material loss that they fail to provide him with the support, reassurance and validation he needs. Within a month, the boy has become aggressive, refuses to attend school, is throwing lit matches at his cousin's cat, has nightmares, is constantly irritable, and does not appear to care about his or others' welfare.

What should the primary care provider do?

(a) Immediately refer the boy to a mental health professional.

(b) Monitor for physical symptoms and suicidal ideation. 
(c) Provide referrals to parents who are also likely to have developed significant traumatic responses.

(d) Make him/herself available to discuss child with teachers and other professionals in need of insight.

(e) All of the above.

\section{Answers}

1. (e): Since the 6-year-old did not demonstrate ongoing symptoms, it is reasonable to assume that the child is doing well and will not present long-term sequelae. Nonetheless, it is important to monitor the child on the next several visits to make sure he has in fact continued to function as expected. Providers may use this opportunity to discuss normal stress responses with parents as a means to normalize and validate their concerns as well as to inquire about their own functioning. The latter is particularly important as parents' mental health status will greatly influence their children's welfare. It is also expected that providers properly document patients' traumatic exposures for future reference.

2. (d): The patient described above is in need of treatment, support, and active participation and coordination between her providers and parents. It is also essential that her parents and teachers be aware of common trauma responses and the need for long-term support and understanding of symptoms in order to prevent misjudging their child and her symptoms.

3. (e): This child is demonstrating symptoms of a severe stress reaction, possibly posttraumatic stress disorder. For this reason, it is important to immediately refer to a qualified mental health professional in order to prevent further exacerbation and to begin treatment. Traumatized children often exhibit somatic complaints and as such, the child must be monitored medically. The child's parents are also likely to be experiencing a severe stress response and as such, would benefit from an evaluation by a mental health professional who may help the family as a whole to manage their respective symptoms and needs.

\section{Conclusions}

Exposure to traumatic events results in psychological distress, whether in relation to events experienced individually or in a major public health emergency. Psychological distress may exacerbate symptoms of physical illness and injury associated with the traumatic events, may be expressed as almost any seemingly unrelated symptom, may intensify the age appropriate fears typical of any child, or may predominantly be exhibited behaviorally. Simple behavioral and environmental interventions are often sufficient to relieve children's distress. Warning signs will identify those children needing professional mental health care.

\section{References}

1. Larzelere MM, Jones GN. Stress and health. Prim Care. 2008;35(4):839-56.

2. Dolan MA, Fein JA, Committee on Pediatric Emergency Medicine. Pediatric and adolescent mental health emergencies in the emergency medical services system. Pediatrics. 2011;127(5):e1356-66.

3. Vogel JM, Vernberg EM. Part 1: children's psychological responses to disasters. J Clin Child Psychol. 1993;22(4):464-84.

4. Tierens M, Bal S, Crombez G, Van de Voorde P, Rosseel Y, Antrop I, Deboutte D. The traumatic impact of motor vehicle accidents in high school students. J Pediatr Psychol. 2012;37(1):1-10.

5. Tierens M, Bal S, Crombez G, Loeys T, Antrop I, Deboutte D. Differences in posttraumatic stress reactions between witnesses and direct victims of motor vehicle accidents. J Trauma Stress. 2012;25(3):280-7.

6. Song SH, Kim BN, Choi NH, Ryu J, McDermott B, Cobham V, Park S, Kim JW, Hong SB, Shin MS, Yoo HJ, Cho SC. A 30-month prospective follow-up study of psychological symptoms, psychiatric diagnoses, and their effects on quality of life in children witnessing a single incident of death at school. J Clin Psychiatry. 2012;73(5):e594-600.

7. Turner HA, Finkelhor D, Ormrod R, Hamby S, Leeb RT, Mercy JA, Holt M. Family context, victimization, and child trauma symptoms: variations in safe, stable, and nurturing relationships during early and middle childhood. Am J Orthopsychiatry. 2012;82(2): 209-19.

8. Abramson D, Redlener I, Stehling-Ariza T, Sury J, Banister A, Park YS. Impact on children and families of the deepwater horizon oil spill: preliminary findings of the coastal population impact study. National Center for Disaster Preparedness, Research Brief 
2010:8. Columbia University Mailman School of Public Health, NY, 2010.

9. Stuber J, Fairbrother G, Galea S, Pfefferbaum B, Wilson-Genderson M, Vlahov D. Determinants of counseling for children in Manhattan after the September 11 attacks. Psychiatr Serv. 2002;53(7): 815-22.

10. Neria Y, Sullivan GM. Understanding the mental health effects of indirect exposure to mass trauma through the media. JAMA. 2011;306(12):1374-5.

11. CDC. Centers for Disease Control and Prevention. Coping with a traumatic event. Atlanta, GA. 2012. http://www.bt.cdc.gov/masscasualties/copingpro.asp. Last Accessed on 15 Mar 2013.

12. Hagan Jr JF, American Academy of Pediatrics Committee on Psychosocial Aspects of Child and Family Health; Task Force on Terrorism. Psychosocial implications of disaster or terrorism on children: a guide for the pediatrician. Pediatrics. 2005;116(3): 787-95.

13. Madrid PA, Grant R, Reilly MJ, Redlener NB. Challenges in meeting immediate emotional needs: short-term impact of a major disaster on children's mental health: building resiliency in the aftermath of Hurricane Katrina. Pediatrics. 2006;117(5 Pt 3): S448-53.

14. Pynoos RS, Steinberg AM, Wraith R. A developmental model of childhood traumatic stress. In: Cicchetti D, Cohen DJ, editors. Developmental psychopathology, Risk, disorder, and adaptation. Wiley series on personality processes, vol. 2. Oxford: Wiley; 1995. p. 72-95.

15. Kanter RK. The 2011 Tuscaloosa tornado: integration of pediatric disaster services into regional systems of care. J Pediatr. 2012;161(3):526-30.

16. Kanter RK, Abramson D. School interventions after the Joplin tornado. PrehospitalDisaster Medicine. In press, 2014.

17. Meredith LS, Eisenman DP, Tanielian T, Taylor SL, Basurto-Davila R, Zazzali J, Diamond D, Cienfuegos B, Shields S. Prioritizing "psychological" consequences for disaster preparedness and response: a framework for addressing the emotional, behavioral, and cognitive effects of patient surge in large-scale disasters. Disaster Med Public Health Prep. 2011; 5(1):73-80.

18. New York State Department of Health. Pediatric and obstetric emergency preparedness toolkit. Albany, NY; 2010. http://www.health.ny.gov/facilities/ hospital/emergency_preparedness/guideline_for_ hospitals/. Last Accessed on 15 Mar 2013.

19. Jaycox LH, Tanielian TL, Sharma P, Morse L, Clum G, Stein BD. Schools' mental health responses after Hurricanes Katrina and Rita. Psychiatr Serv. 2007; 58(10):1339-43.

20. Madrid PA, Garfield R, Jaberi P, Daly M, Richard G, Grant R. Mental health services in Louisiana school based health centers post-hurricanes Katrina and Rita. Prof Psychol Res Pract. 2008;39(1):45-51.
21. Pfefferbaum B, Call JA, Sconzo GM. Mental health services for children in the first two years after the 1995 Oklahoma City terrorist bombing. Psychiatr Serv. 1999;50(7):956-8.

22. McLaughlin KA, Fairbank JA, Gruber MJ, Jones RT, Osofsky JD, Pfefferbaum B, Sampson NA, Kessler RC. Trends in serious emotional disturbance among youths exposed to Hurricane Katrina. J Am Acad Child Adolesc Psychiatry. 2010;49(10):990-1000.

23. Abramson D, Park YS, Stehling-Ariza T, Redlener I. Children as bellwethers of recovery: dysfunctional systems and the effects of parents, households, and neighborhoods on serious emotional disturbance in children after Hurricane Katrina. Disaster Med Public Health Prep. 2010;4:S17-27.

24. Peek L, Stough LM. Children with disabilities in the context of disaster: a social vulnerability perspective. Child Dev. 2010;81(4):1260-70.

25. Mullen M. The conversation. The Atlantic. 2012; 310:26.

26. Klonsky DE, Muehlenkamp JJ. Self-injury: a research review for the practitioner. J Clin Psychol. 2007; 63(11):1045-56.

27. Connors R. Self-injury in trauma survivors: 1.Functions and meanings. Am J Orthopsychiatry. 1996;66(2):197-206.

28. Zoroglu SS, Tuzun U, Sar V, Tutkun H, Savaçs HA, Ozturk M, Alyanak B, Kora ME. Suicide attempt and self-mutilation among Turkish high school students in relation with abuse, neglect, and dissociation. Psychiatry Clin Neurosci. 2003;57(1):119-26.

29. Murray CD, Macdonald S, Fox J. Body satisfaction, eating disorders and suicide ideation in an internet sample of self-harmers reporting and not reporting childhood sexual abuse. Psychol Health Med. 2008;13(1):29-42.

30. Goldston DB, Daniel SS, Erkanli A, Reboussin BA, Mayfield A, Frazier PH, Treadway SL. Psychiatric diagnoses as contemporaneous risk factors for suicide attempts among adolescents and young adults: developmental changes. J Consult Clin Psychol. 2009; 77(2):281-90.

31. Souza LD, Silva RA, Jansen K, Kuhn RP, Horta BL, Pinheiro RT. Suicidal ideation in adolescents aged 11 to 15 years: prevalence and associated factors. Rev Bras Psiquiatr. 2010;32(1):37-41.

32. Russell ST, Toomey RB. Men's sexual orientation and suicide: evidence for U.S. adolescent-specific risk. Soc Sci Med. 2012;74(4):523-9.

33. Klomek AB, Sourander A, Niemelä S, Kumpulainen K, Piha J, Tamminen T, Almqvist F, Gould MS. Childhood bullying behaviors as a risk for suicide attempts and completed suicides: a population-based birth cohort study. J Am Acad Child Adolesc Psychiatry. 2009;48(3):254-61.

34. Stevens SJ, Murphy BS, McKnight K. Traumatic stress and gender differences in relationship to substance abuse, mental health, physical health, and HIV risk behavior in a sample of adolescents enrolled in drug treatment. Child Maltreat. 2003;8(1):46-57. 
35. Caldwell BA, Redeker N. Sleep and trauma: an overview. Issues Ment Health Nurs. 2005;26(7):721-38.

36. Bender W, Sims R. Katrina kids! helping kids exposed to population-wide trauma. Teach Except Child. 2007;40(1):40-7.

37. Crundwell RMA. Identifying and teaching children with selective mutism. Teach Except Child. 2006;38(3):48-55.

38. Baldry AC, Farrington DP. Protective factors as moderators of risk factors in adolescence bullying. Soc Psychol Educ. 2005;8(3):263-84.

39. Cohen E, Chazan S, Lerner M, Maimon E. Posttraumatic play in young children exposed to terrorism: an empirical study. Inf Mental Health J. 2010;31(2):159-81.

40. Armsworth MW, Holaday M. The effects of psychological trauma on children and adolescents. J Couns Dev. 1993;72(4):49-56.

41. Morales JR, Guerra NG. Effects of multiple context and cumulative stress on urban children's adjustment in elementary school. Child Dev. 2006;77(4):907-23.

42. Duplechain R, Reigner R, Packard A. Striking differences: the impact of moderate and high trauma on reading achievement. Read Psychol. 2008;29(2):117-36.

43. Porche MV, Fortuna LR, Lin J, Alegria M. Childhood trauma and psychiatric disorders as correlates of school dropout in a national sample of young adults. Child Dev. 2011;82(3):982-98.

44. Thanasiu PL. Childhood sexuality: discerning healthy from abnormal sexual behaviors. J Mental Health Couns. 2004;26(5):309-19.
45. Masi G, Mucci M, Millepiedi S. Separation anxiety disorder in children and adolescents: epidemiology, diagnosis and management. CNS Drugs. 2001; 15(2):93-104.

46. Hoven CW, Duarte CS, Wu P, Erickson EA, Musa GJ, Mandell DJ. Exposure to trauma and separation anxiety in children after the WTC attack. Appl Dev Sci. 2004;8(4):172-83.

47. Cohen JA, Kelleher KJ, Mannarino AP. Identifying, treating, and referring traumatized children. The role of pediatric providers. Arch Pediatr Adolesc Med. 2008;162(5):447-52.

48. Saunders BE, Berliner L, Hanson RF, editors. Child physical and sexual abuse: guidelines for treatment (Revised Report: April 26, 2004). Charleston, SC: National Crime Victims Research and Treatment Center; 2004. http://academicdepartments.musc.edu/ ncvc/resources_prof/ovc_guidelines04-26-04.pdf. Last Accessed on 15 Mar 2013.

49. Cohen JA, Mannarino AP, Deblinger E, editors. Traumafocused cognitive behavioral therapy for children and adolescents. New York, NY: The Guilford Press; 2012.

50. Foa EB, Chrestman KR, Gilboa-Schectman E. Prolonged exposure therapy for adolescents with PTSD: emotional processing of traumatic experiences. New York, NY: Oxford University Press; 2009.

51. Pynoos RS, Eth S. Witness to violence: the child interview. J Am Acad Child Psychiatry. 1986; 25(3):306-19.

52. Gil E. The healing power of play: working with abused children. New York, NY: The Guildford Press; 1991. 